\title{
The effectiveness of temperature control of thermocyclers in PCR optimization
}

$\overline{\text { Elisa A Santos }^{\star, \neq, 1,2}, \text { Roberto M Ichinose }^{\ddagger, 1} \text { \& Rosimary T Almeida }}$

\section{ABSTRACT}

This study evaluated the effectiveness of thermocycler temperature control, considering the influence of other determinant factors for the optimization of PCR. The reduction in the number of repeated PCR tests, applied in the diagnosis and prognosis of chronic myeloid leukemia at the National Cancer Institute in Brazil, was used as a measure of effectiveness. This indicator was evaluated using samples obtained before and after the temperature control in the wells of the thermocyclers. There was a reduction of $18.9 \%$ in the number of repeated exams in the second sample. A structured interview with laboratory staff indicated that there was no change in the other determinant factors.

\section{METHOD SUMMARY}

This work describes a method of temperature control in thermocycler wells and evaluates its effectiveness in the molecular biology laboratory, even with the influence of other determinants for PCR optimization.

\section{KEYWORDS}

optimization $\cdot$ polymerase chain reaction $\cdot$ thermocyclers

- temperature control

'Biomedical Engineering Program of the Alberto Luiz Coimbra Institute for Graduate Studies \& Research in Engineering of the Federal University of Rio de Janeiro, Centro de Tecnologia, Bloco H, Sala 327, 21941-914, Brazil; ${ }^{2}$ Clinical Engineering Service, José Alencar Gomes da Silva National Cancer Institute, Rio de Janeiro, RJ, R. André Cavalcanti 37, 20231-050, Brazil; *Author for correspondence:elisa@peb.ufrj.br; ¥These authors contributed equally to this work

BioTechniques 67: 271-275 (December 2019) 10.2144/btn-2018-0177
Optimization of PCR is dependent on both the quality and quantity of the elements composing the reaction, as well as the reaction temperatures, laboratory infrastructure and the training of specialized staff members [1-10]. Multiple factors may affect the amplification of PCR, thus interfering with the outcomes of several molecular biology procedures [11], such as pyrosequencing [12] and NGS [13].

The thermocycler, the equipment that provides the cycles of temperatures required by PCR, is recognized as a reliable and stable technology that is widely used in molecular diagnostics [14]. However, despite this confidence, Schoder et al. [9] warned about the lack of studies on the performance of this equipment.

The inappropriate use of the thermocycler has been associated with undesired PCR results, including failure of PCR results standards [15], distortions in the random amplified polymorphic DNA PCR process [8], and distortions in the multiplex-PCR process [10]. Kapley et al. highlighted the importance of temperature parameters to obtain efficiency in the establishment of a multiplex-PCR protocol [16]. The College of American Pathologists recommends periodic verification of temperatures in the thermocycler wells [1]. In cases of diagnostic tests carried out by PCR, the lack of temperature control may lead to false-negative results or inconclusive results, implying the need for repetition of exams and a subsequent increase in costs.

In this scenario, the objective of the present work was to evaluate the effectiveness of thermocycler temperature control for PCR optimization, considering other determinant factors in this process. To achieve this purpose, data from exams in chronic myeloid leukemia at the Bone Marrow Transplantation Center of the National Cancer Institute (INCA) were used. In addition, an assay containing homoge- neous samples to verify the performance of the thermocyclers was carried out, and procedures for controlling temperature in the wells of the thermocyclers were also performed.

\section{MATERIALS \& METHODS}

Assay to verify the performance of thermocyclers

The first stage of the study was carried out in the Laboratory of Clinical Research of the INCA Research Center, with the aim of verifying the performance of the thermocyclers. The assay was performed with homogeneous samples for $b$-actin gene amplification, obtained with ultrapure water, Taq polymerase enzyme stored at $-80^{\circ} \mathrm{C}$, adequate amounts of buffer solution, and dNTPs for a total of 45 homogeneous samples. The integrity of the samples was checked by spectrophotometry.

Three 96-well thermocyclers were used simultaneously, each receiving 15 samples. The choice of wells was the same used by Nolan and bustin [4] to study the thermal uniformity between blocks of different brands of thermocyclers. The following temperature protocol was established: initial denaturation at $94^{\circ} \mathrm{C}$ for $5 \mathrm{~min} ; 25$ cycles of denaturation at $94^{\circ} \mathrm{C}$ for $30 \mathrm{~s}$; annealing at $59^{\circ} \mathrm{C}$ for $30 \mathrm{~s}$; extension at $72^{\circ} \mathrm{C}$ for $30 \mathrm{~s}$; and a final extension at $72^{\circ} \mathrm{C}$ for $10 \mathrm{~min}$. For the electrophoresis, performed at $100 \mathrm{~V}$ for $30 \mathrm{~min}, 5 \mu \mathrm{l}$ of the amplified sample was applied to agarose gel stained with $2 \%$ gel red.

\section{Verification \& temperature control of thermocyclers}

The second stage comprised establishing the conditions for the verification and control of temperature in the wells of the thermocycler. A commercial thermocycler analyzer (model TAS, brand Hain Lifescience $\mathrm{GmbH}$, Nehren, Germany) was used. Its accuracy is $\pm 0.1^{\circ} \mathrm{C}$, with sensors that have a response time less than $200 \mathrm{~ms}$. Figure 1 , 


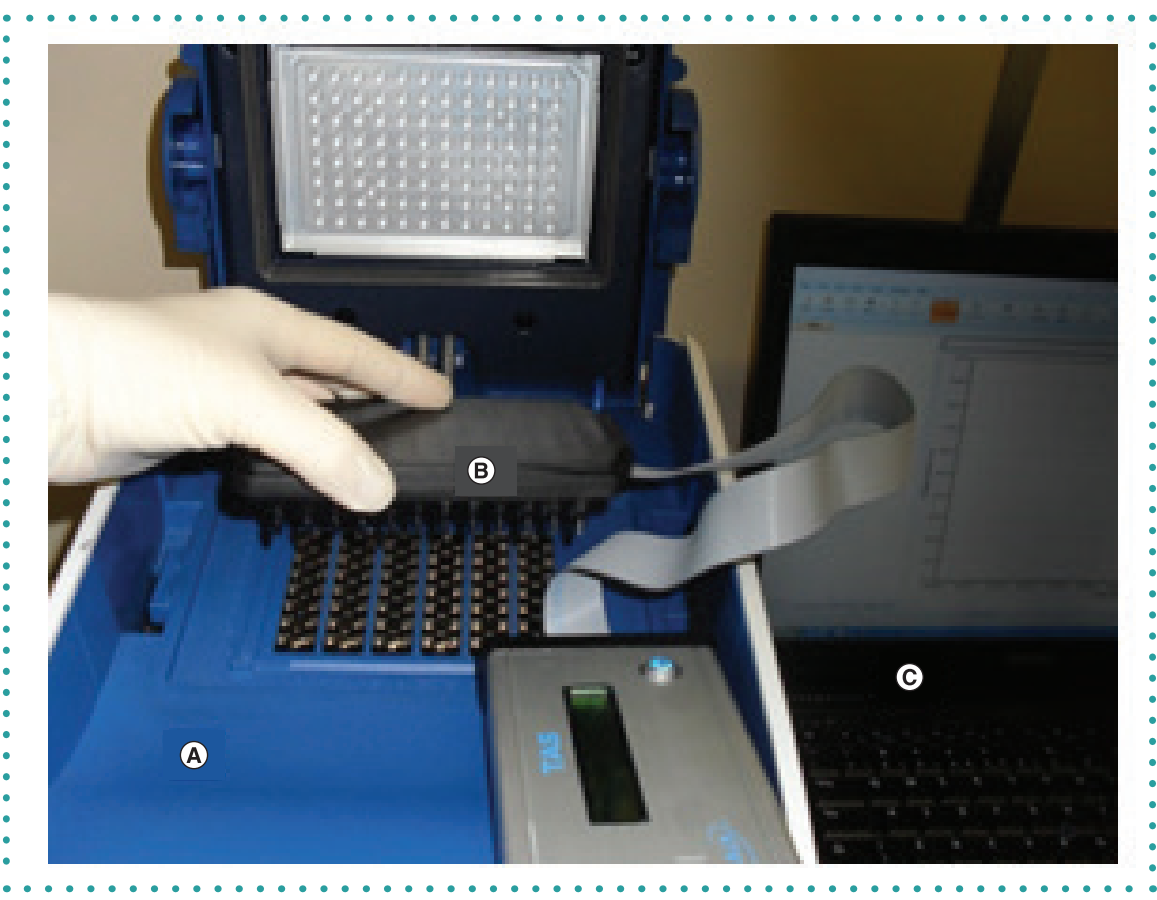

Figure 1. Thermocycler before modification. (A) Thermocycler with open lid , (B) thermocycler analyzer with the sensors directly connected to the thermocycler and (C) microcomputer.

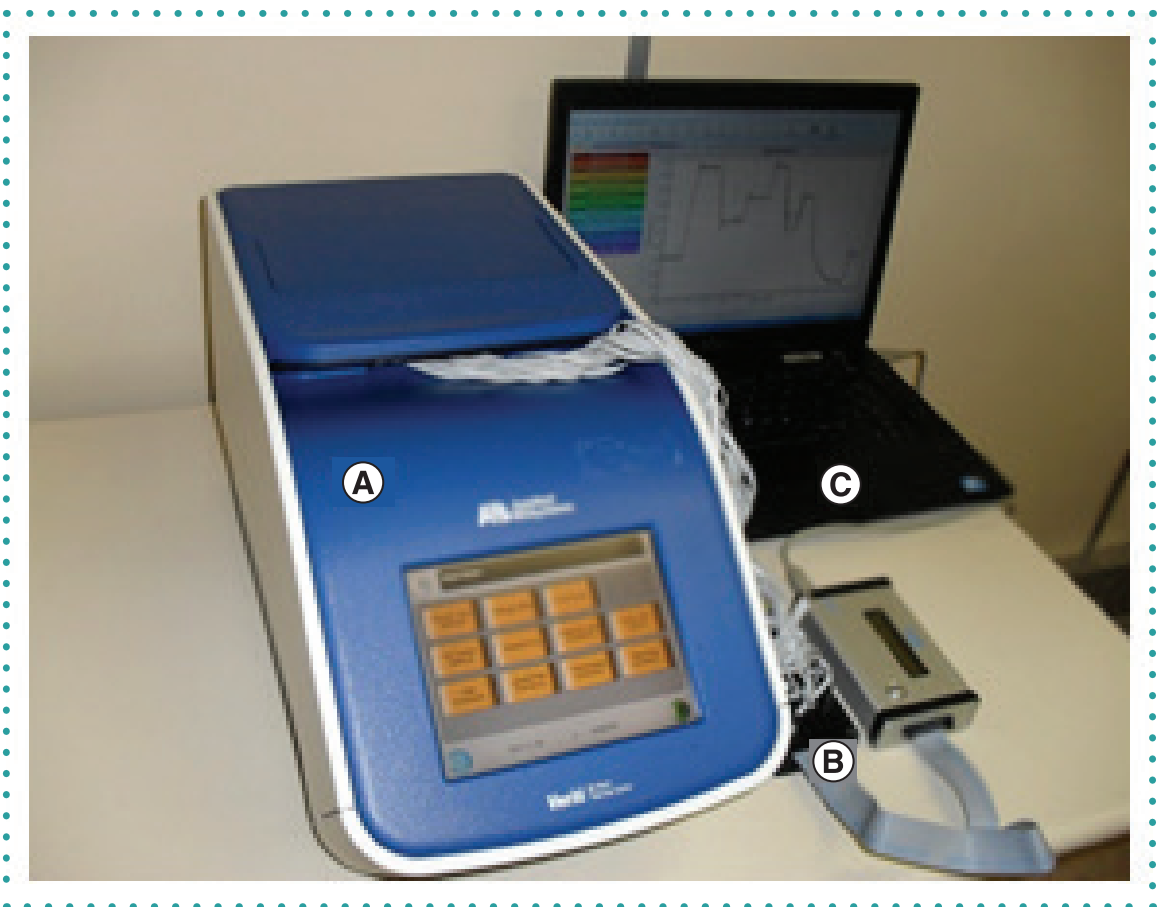

Figure 2. Thermocycler after modification. (A) Thermocycler with closed lid, (B) thermocycler analyzer with new sensors inside the thermocycler and (C) microcomputer.

D shows the thermocycler analyzer in its original version prepared for temperature measurement with the thermocycler lid open, since the positioning of the plate with the temperature sensors prevents its closure.
28AWG 65-cm extension cables were used to allow measurement of the temperature with the thermocycler lid closed. The encapsulation of each PT100 cell was reduced from a height of $2.8 \mathrm{~cm}$ to a height of $1.8 \mathrm{~cm}$. The new sensor configuration is presented in Figure 2.

The thermocycler analyzer and the modified sensors were calibrated in the Brazilian Calibration Network (accredited by the National Institute of Metrology, Quality, and Technology) laboratory in order to verify the measurement of uncertainty associated with the temperature measurement instrument. A total of 22 sensors were calibrated at temperatures of $4,55,72$ and $95^{\circ} \mathrm{C}$. Of these 22 calibrated sensors, 18 that obtained associated measurement uncertainty of up to $0.10^{\circ} \mathrm{C}\left(55\right.$ and $72^{\circ} \mathrm{C}$ ) and $0.22^{\circ} \mathrm{C}\left(95^{\circ} \mathrm{C}\right)$ were chosen for the development of this work. A 96-well thermal block consisting of 12 columns coded from 1 to 12 and 8 lines coded from $A$ to $H$ was chosen. The following wells were used: $A 1$, A4, A7, A10, A12, C5, D1, A3, A7, A7, D7, D8, E4, E10, E11, G5, H1, H3, H7, H10 and H12. The standard value for the heated lid of the thermocycler was $105^{\circ} \mathrm{C}$ and the ramp rate ranged from 2.3 to $4.0^{\circ} \mathrm{C} / \mathrm{s}$ depending on the model of the thermocycler.

The following procedures were established for measurements and temperature control.

\section{Procedure for verification of thermocycler temperature}

a) Check room temperature and humidity, and clean the thermocycler and workbench; b) Set the 18 sensors in the wells of the thermocycler block;

c) Connect the thermocycler analyzer to the computer and the sensors, and start the measurement software;

d) Program the thermocycler with the following temperature cycle protocol: $1 \mathrm{~min}$ at $95^{\circ} \mathrm{C} ; 2$ min at $4^{\circ} \mathrm{C} ; 1 \mathrm{~min}$ at $95^{\circ} \mathrm{C} ; 1 \mathrm{~min}$ at $30^{\circ} \mathrm{C} ; 1 \mathrm{~min}$ at $95^{\circ} \mathrm{C} ; 1 \mathrm{~min}$ at $55^{\circ} \mathrm{C} ; 1 \mathrm{~min}$ at $72^{\circ} \mathrm{C} ; 30$ s at $95^{\circ} \mathrm{C} ; 30$ s at $72^{\circ} \mathrm{C} ; 2$ min at $4^{\circ} \mathrm{C}$; heated lid at $105^{\circ} \mathrm{C}$; initiate temperature data acquisition (perform three replicates).

The PT100 sensors of the thermocycler analyzer were modified in the Clinical Engineering laboratory of INCA in order to avoid any effects of the ambient temperature shown in the process of verifying the thermocycler temperature [17]. Type

\section{Procedure for thermocycler} temperature control

a) Calculate the temperature accuracy of the sensors in the well of thermocycler (done according to the ISO/IEC guidance for calcu- 


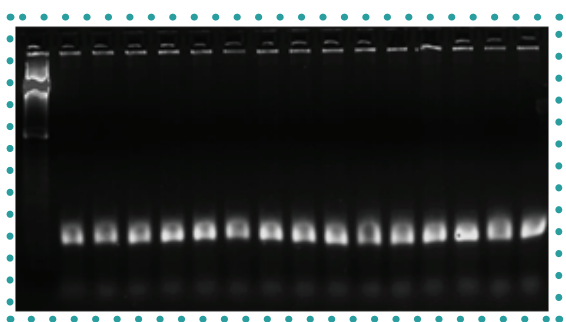

Figure 3. Gel image showing an example of PCR results with good gene expression in all 15 wells of the thermal block.

lation of measurement uncertainties [18]) and calculate the temperature uniformity in the thermal block;

b) Compare the temperature values (accuracy and uniformity) with the manufacturer's specifications and the control limit $(\mathrm{CL})$ established in this work to analyze the suitability of the equipment for use. The $\mathrm{CL}$ defined for accuracy was $[T-1.0, T+10]^{\circ} \mathrm{C}$ and the $\mathrm{CL}$ for uniformity was below $1.5^{\circ} \mathrm{C}$; where $T=$ programmed temperature in the thermocycler;

c) Remove any equipment with nonconformity to $C L$ from use;

d) Send thermocyclers with nonconformity of temperature for maintenance.

\section{Assessment of the effectiveness of the} temperature control of thermocyclers

This assessment was performed in the Laboratory of Molecular Biology of the Bone Marrow Transplantation Center (CEMO) of INCA, considering data from examinations before (2011) and after (2013) the implementation of thermocycler temperature control. A retrospective study was carried out in the physical records of the qualitative rearrangement $B C R / A B L$ $\mathrm{t}(9 ; 22)$ using RT-PCR to diagnose and control the treatment of chronic myeloid leukemia (CML). This study used examinations for initial diagnosis of CML, posttransplant follow-up of bone marrow and genetic mutations. A random sample of $30 \%$ of eligible examinations was obtained in each period. To evaluate the effectiveness of this thermocycler control, the "number of examinations with recommendation for repetition" was chosen as the indicator.

The identification of the determinant factors for optimization of PCR was carried out by reviewing the literature [1-10], which indicated 16 basic factors: DNA sample,

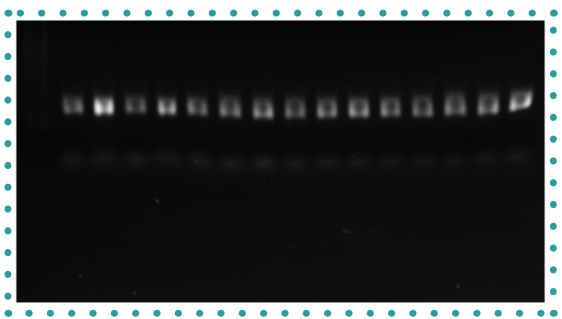

Figure 4. Gel image showing an example of PCR with low gene expression in well 1 and in wells $3-15$.

enzyme polymerase; dNTPs; primers; annealing temperature; melting temperature; temperature cycles; buffer solution; magnesium; positive and negative controls; written procedure for DNA sample; written procedures for PCR; qualified human resources; environment and workflow; thermocycler; and pipette. A structured interview of those responsible for the laboratory was carried out to evaluate the conditions of these factors during the study periods.

\section{RESULTS \& DISCUSSION}

The results of the DNA amplification assay of homogeneous samples showed that only one thermocycler performed as expected (Figure 3). The other thermocyclers presented reactions with different gene expressions (Figure 4) or faulty reactions

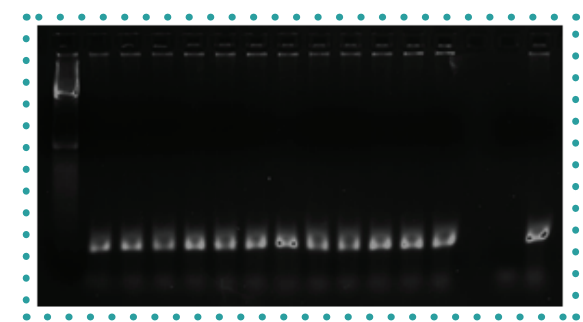

Figure 5. Gel image showing PCR with failures in wells 13 and 14 .

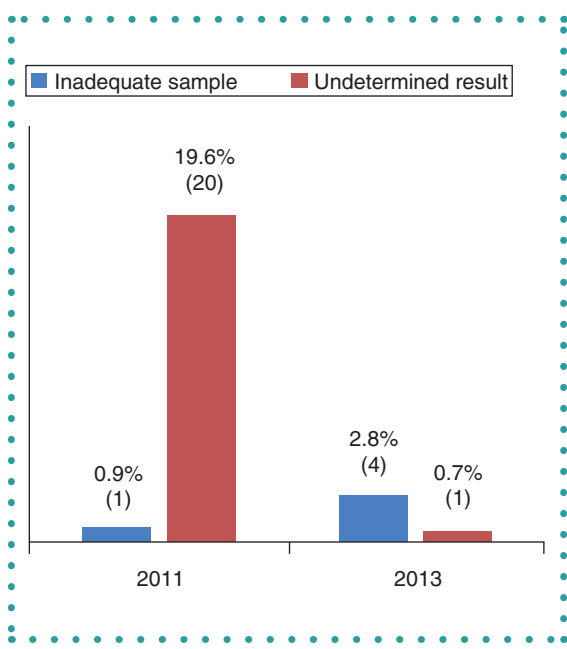

Figure 6. Exams with a recommendation to repeat. Percentage of exams with a recommendation to repeat due to inadequate sample (blue) and the undetermined result (red).

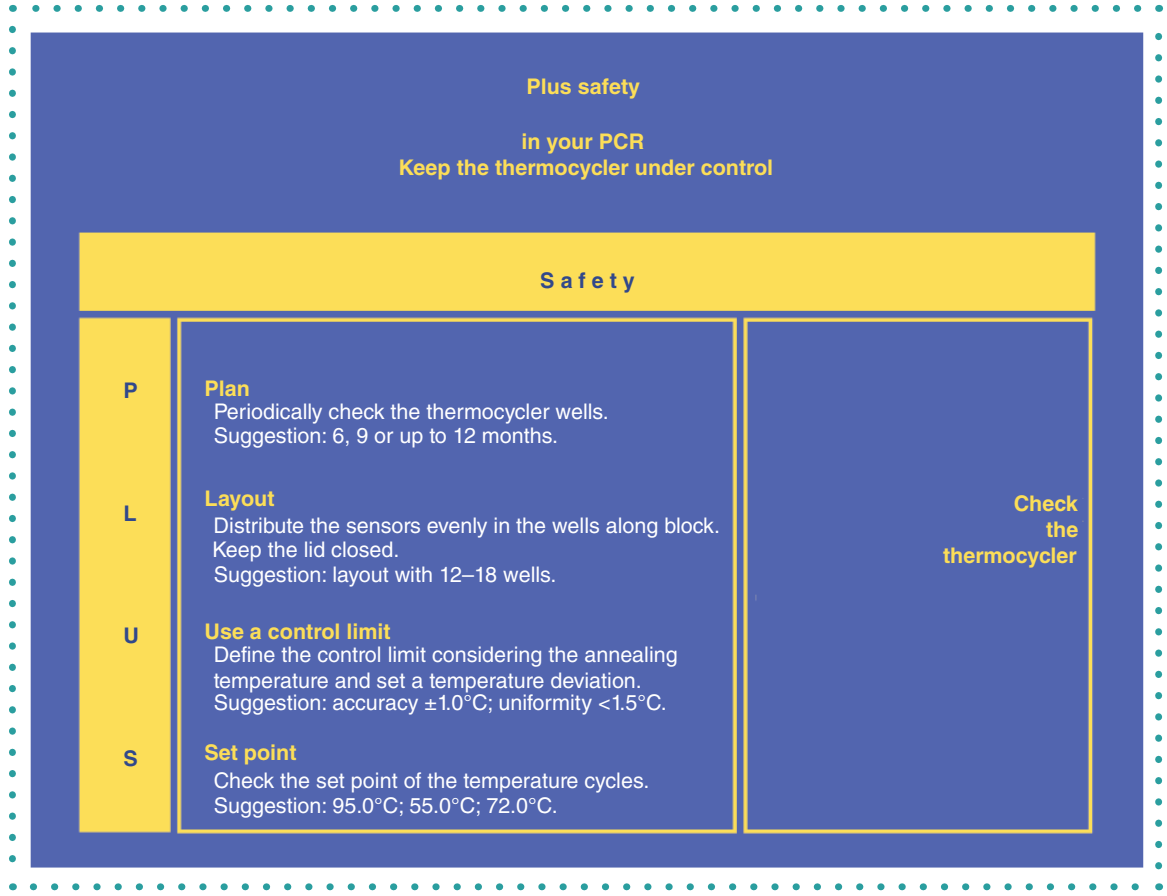

Figure 7. Recommendations for keeping the thermocyclers under control. 


\begin{tabular}{|c|c|}
\hline $\begin{array}{l}\text { Determinant } \\
\text { factors of PCR }\end{array}$ & Conditions in the laboratory \\
\hline DNA sample & $\begin{array}{l}\text { There is a record of the method of obtaining the target DNA sample } \\
\text { There was no change in the method } \\
\text { It follows a standard laboratory protocol }\end{array}$ \\
\hline $\begin{array}{l}\text { Enzyme DNA poly- } \\
\text { merase }\end{array}$ & $\begin{array}{l}\text { There is a record of the type of enzyme } \\
\text { There was no change in the enzyme } \\
\text { Only prequalified and approved brands were purchased }\end{array}$ \\
\hline dNTPs & $\begin{array}{l}\text { There is a record of the characteristics of dNTP } \\
\text { There was no change in dNTPs } \\
\text { Only prequalified and approved brands were purchased }\end{array}$ \\
\hline Primer & $\begin{array}{l}\text { There is a record of the dNTP sequences } \\
\text { There was no change in the sequence and characteristics of dNTPs } \\
\text { Only prequalified and approved brands were purchased }\end{array}$ \\
\hline $\begin{array}{l}\text { Annealing } \\
\text { temperature }(\mathrm{Ta})\end{array}$ & $\begin{array}{l}\text { There is a record of } \mathrm{Ta} \text {. Ta refers to } \mathrm{Tm} \\
\text { There was no change in } \mathrm{Ta}\end{array}$ \\
\hline $\begin{array}{l}\text { Melting } \\
\text { temperature (Tm) }\end{array}$ & $\begin{array}{l}\text { There is a record of Tm } \\
\text { Tm is calculated based on the amount of dNTPs } \\
\text { There was no change in Tm }\end{array}$ \\
\hline $\begin{array}{l}\text { Cycles of } \\
\text { temperature }\end{array}$ & $\begin{array}{l}\text { There is a record of the temperature cycles } \\
\text { There was no change in temperature cycles }\end{array}$ \\
\hline Buffer solution & $\begin{array}{l}\text { There is a record of the buffer solution } \\
\text { There was no change in buffer solution } \\
\text { The buffer solution is supplied with the enzyme }\end{array}$ \\
\hline Magnesium & $\begin{array}{l}\text { There is a record of the magnesium } \\
\text { There was no change } \\
\text { Magnesium is contained in the buffer solution supplied with the enzyme }\end{array}$ \\
\hline $\begin{array}{l}\text { Positive and } \\
\text { negative controls }\end{array}$ & $\begin{array}{l}\text { There is a record of the controls } \\
\text { There was no change } \\
\text { Only controls approved in chronic myeloid leukemia are used } \\
\text { Concentrations of lines k652 and Kasumi were used for positive control }\end{array}$ \\
\hline $\begin{array}{l}\text { Written procedure } \\
\text { for DNA sample }\end{array}$ & $\begin{array}{l}\text { There is a written operating procedure } \\
\text { There was no change in the procedure }\end{array}$ \\
\hline $\begin{array}{l}\text { Written procedures } \\
\text { for PCR } \\
\text { - Rearrangement } \\
\text { t(9;22) } B C R / A B L \\
\text { RT-PCR multiplex } \\
\text { and nested }\end{array}$ & $\begin{array}{l}\text { There are written operational procedures } \\
\text { There were no changes in procedures }\end{array}$ \\
\hline $\begin{array}{l}\text { Qualified human } \\
\text { resources }\end{array}$ & $\begin{array}{l}\text { There is qualified and experienced staff to perform the exams } \\
\text { There was a partial replacement of the staff, but no change in their } \\
\text { qualification }\end{array}$ \\
\hline $\begin{array}{l}\text { Environment and } \\
\text { workflow }\end{array}$ & $\begin{array}{l}\text { There are environments for the pre- and post-PCR phases } \\
\text { There is a workflow control in these environments } \\
\text { There was no change in the environments and in the workflows }\end{array}$ \\
\hline Pipettes & $\begin{array}{l}\text { There is an annual verification of the pipette volume } \\
\text { There was no change in the procedure }\end{array}$ \\
\hline
\end{tabular}

> (Figure 5). These undesirable PCR results can be attributed to failures in thermocycler temperature control.

The temperature control procedures were applied in 41 thermocyclers at INCA and produced the following results: 23 showed good conditions; 16 were indicated for preventive maintenance due to deviations in the temperature; and 2 were indicated for maintenance due to malfunction.
The "number of exams with recommendation for repetition" revealed a reduction after the intervention, decreasing from $21(20.5 \%)$ in 2011 to $5(3.5 \%)$ in 2013. Figure 6 details this finding, in which the number of examinations with undetermined PCR results showed a reduction of 18.9 percentage points and the number of examinations with inadequate sample had an increase of 1.9 percentage points.

The results of the staff interview on the determinant factors of PCR in the CEMO/ INCA laboratory are given in Table 1, which showed no change among the majority of the factors during the period from 2011 to 2013. Although there was a partial replacement of the laboratory staff, their qualification and experience have not changed.

Thus, the conditions of the 15 items of the form were satisfactory, taking into account the necessary conditions established to guarantee the performance of the PCR. The only determinant factor of PCR described in the literature [1-9] that suffered alteration was the temperature in the wells of the thermocyclers.

The determinant factors for the optimization of PCR did not differ in the periods of study, except for corrections made in the thermocyclers. Hence, it is reasonable to attribute the reduction in the number of recommendations to repeat exams with the undetermined result to the thermocycler temperature control intervention. The increase in the number of exams with an inadequate sample, observed in 2013 , can be explained by the increase in the number of exams performed with samples from other institutions, since the laboratory expanded the service it was offering to the regional healthcare system.

In this study, no false results were identified; however, undetermined PCRw results could lead to false-negative results in an environment with control failure during the examinations. The nonoccurrence of false results can be attributed to the peculiarity of the laboratory, recognized as a reference in Brazil for the evaluation of CML, with activities such as teaching, research, diagnosis, treatment and follow-up of patients with bone marrow transplantation.

It is worth mentioning that studies on the multiple factors that influence the 
performance of PCR are still important, considering that PCR errors occur in many DNA coding techniques, even in NGS, and contribute to failures in genetic analyses [13]. Studies relating to the fidelity of the enzyme DNA polymerase would be examples of this $[11,13,19,20]$.

Regarding the temperature measurement of the thermocyclers, it is important to consider some specific aspects that characterize the changes of the temperature cycles with the potential to impact the PCR results. One aspect is the heating and cooling rates, which are important for determining the transition time between PCR steps and the total reaction time. These ramp rates have the potential to interfere with PCR cycle temperature accuracy when they deviate significantly from the manufacturer's specifications. In this work, it was observed that equipment with a ramp rate of less than $65 \%$ of the value specified by the manufacturer were removed due to the nonconformity to the temperature control limit adopted here.

Another important aspect to be considered is the occurrence of over- and under-shoots in temperature curves. The measurements performed revealed that the over- and under-shoots observed at the beginning of the cycle had a relatively short period of time, with amplitude variation up to $\pm 5.5^{\circ} \mathrm{C}$ and a time interval of 6-8 s. These variations were not enough to compromise the equipment conformity to the control limits. A PCR control test with homogeneous samples was performed on one of these pieces of equipment and showed good performance, with amplification expected in the 15 wells evaluated.

Some recommendations can be presented to guide laboratories in PCR optimization. In this sense, a summary of the main recommendations was elaborated based on four essential aspects: periodic check planning; layout of sensor disposition in the wells; user control limits; and set point of temperature cycles. The acronym PLUS Safety was created with the aim of emphasizing the importance of such aspects for the safe accomplishment of a PCR (Figure 7). In the absence of a thermocycler analyzer, users are encouraged to make control tests using homogeneous samples to evaluate the performance of the thermocycler.

\section{FUTURE PERSPECTIVE}

The assessment of the effectiveness of temperature control of thermocyclers showed that the intervention was effective in reducing the repetition of undetermined exams by PCR, and can also represent a cost saving for the institution. These findings have alerted us to the need for a systematic control of the temperature of the thermocycler, which is sometimes neglected due to excessive reliance on the equipment.

Finally, it is worth mentioning that the methodology developed in this work could be extended to quantitative thermocyclers.

\section{AUTHOR CONTRIBUTIONS}

EAS and RMI defined the parameters and the procedures for the thermocycler temperature control. EAS and RTA established the methodology to assess the effectiveness of the intervention. All authors contributed to the writing and to the reviewing of the manuscript.

\section{FINANCIAL \& COMPETING INTERESTS DISCLOSURE}

This work was supported by the José Alencar Gomes da Silva National Cancer Institute and the Biomedical Engineering Program of the Alberto Luiz Coimbra Institute for Graduate Studies and Research in Engineering of the Federal University of Rio de Janeiro, as well as the Coordenação de Aperfeiçoamento de Pessoal de Nível Superior - CAPES Foundation within the Ministry of Education. The authors have no other relevant affiliations or financial involvement with any organization or entity with a financial interest in or financial conflict with the subject matter or materials discussed in the manuscript apart from those disclosed.

No writing assistance was utilized in the production of this manuscript.

\section{ETHICAL CONDUCT OF RESEARCH}

The Research Ethics Committee of the Brazilian National Cancer Institute (INCA) approved the use of qualitative rearrangement records $B C R / A B L t(9 ; 22)$ used in this work, according to the opinion number 1.586.987, project CAAE
55039316.6.3001.5274 of the Federal University of Rio de Janeiro.

\section{OPEN ACCESS}

This work is licensed under the AttributionNonCommercial-NoDerivatives 4.0 Unported License. To view a copy of this license, visit http://creativecommons.org/ licenses/by-nc-nd/4.0/

\section{REFERENCES}

1. College of American Pathologists (CAP). Molecula pathology checklist. Northfield, IL, USA (2015).

2. WHO. Handbook: good laboratory practice (GLP): quality practices for regulated non-clinical research and development. WHO, Geneva, Switzerland (2010).

3. Organisation for Economic Co-operation and Development. OECD guidelines for quality assurance in molecular genetic testing. OCDE (2007).

4. Nolan T, Bustin SA. PCR Technology: Current Innovations (3rd Edition). CRC Press, FL, USA (2013).

5. Altshuler ML. PCR Troubleshooting: The Essential Guide (1st Edition). Caister Academic Press, Norfolk, UK (2006).

6. Mcpherson MJ, Møller SG. PCR (2nd Edition). Taylor \& Francis Group, NY, USA (2006)

7. Kennedy S, Oswald N. PCR Troubleshooting and Optimization: The Essential Guide. Horizon Scientific Press, Norfolk, UK (2011).

8. Saunders GC, Dukes J, Parkes HC, Cornett JH. Interlaboratory study on thermal cycler performance in controlled PCR and random amplified polymorphic DNA analyses. Clin. Chem. 47(1), 47-55 (2001).

9. Schoder D, Schmalwieser A, Schauberger G, Hoorfar J, Kuhn M, Wagner M. Novel approach for assessing the performance of PCR cyclers used for diagnostic testing. J. Clin. Microbiol. 43(6), 2724-2728 (2005).

10. Kim YH, Yang SB, Park SR. Performance evaluation of thermal cyclers for PCR in a rapid cycling condition. BioTechniques 44(4), 495-505 (2008)

11. Blow N. PCR's next wave. BioTechniques 62(4), 149-152 (2017)

12. Pinto AJ, Raskin L. PCR Biases distort bacterial and archaeal community in pyrosequencing datasets. PLOS ONE 7(8), e43093 (2012)

13. Potapov V, Ong JL. Examining sources of error in PCR by single-molecule sequencing. PLoS ONE 12(1) e0169774 (2017).

14. Ecri Institute (ECRI). Healthcare Product Comparison System.

15. Schoder D, Schmalwieser A, Schauberger G, Kuhn M Hoorfar J, Wagner M. Physical characteristics of six new thermocyclers. Clin. Chem. 49(6), 960-963 (2003).

16. Kapley A, Lampel K, Purohit HJ. Thermocycling steps and optimization of multiplex PCR. Biotechnol. Lett. 22(24), 1913-1918 (2000).

17. Santos EA, Sternberg C, Almeida RT. Influência da temperatura ambiente na análise do termociclador. XXIV Congresso Brasileiro de Engenharia Biomédica CBEB, Uberlândia, Brazil (2014).

18. International Organization for Standardization (ISO) International Electrotechnical Commission (IEC) Uncertainty of measurement Part 3: guide to the expression of uncertainty in measurement. ISO/IEC 98-3 2008 Guide, Geneva, Switzerland (2008).

19. McInerney $P$, Adams $P$, Haidi MZ. Error rate comparison during polymerase chain reaction by DNA polymerase. Hindawi Publishing Corporation. Mol. Biol. Int. 287430 (2014).

20. Lubock NB, Zhang D, Sidore AM, Church GM, Kosuri S. A systematic comparison of error correction enzymes by next-generation sequencing. Nucleic Acids Res. 45(15), 9206-9217 (2017). 